\title{
Antifertility effect of sympathomimetic drugs on male rats when applied locally to the vas deferens*
}

\author{
W. D. Ratnasooriya $\nmid$, D. P. Gilmore and R. M. Wadsworth \\ Institute of Physiology, Glasgow University, Glasgow G12 8QQ, and \\ $\ddagger$ Department of Physiology and Pharmacology, University of Strathclyde, \\ Glasgow G1 $1 X W$, U.K.
}

\begin{abstract}
Summary. Local application of collars containing $25 \%$ methoxamine, $50 \%$ or $75 \%$ tyramine or $50 \%$ norephedrine to both vasa deferentia of rats caused a reduction in fertility but not in their ability to mate. A gradual return to fertility was seen in those animals which received the lower dose of tyramine or norephedrine, while the other treatments caused a permanent reduction in fertility. The cause of sterility was production of azoospermic ejaculates resulting from either a block in sperm transport in the vas deferens or from a deficiency in the ejaculatory mechanism. Only methoxamine caused a mechanical obstruction of the vas deferens, but it is possible that the other drugs caused a sustained spasm. An emission defect could have been due to transmitter depletion, receptor-specific desensitization or presynaptic $\alpha$-adrenoreceptor-mediated inhibition. Spermatozoa from the cauda epididymidis were immotile following the treatments.
\end{abstract}

\section{Introduction}

Several studies have shown that sympathomimetic drugs cause rhythmic contractions in isolated vasa deferentia (Martins, Valle \& Porto, 1940; Ventura, Freund, Davis \& Pannati, 1973; McLeod, Reynolds \& Demaree, 1973; Hepperlen, Dalske \& Lacy, 1976; Anton \& McGrath, 1977). Such contractions have also been produced in vivo when the drugs were applied locally to the vas deferens from a slow-release depot (Ratnasooriya, Wadsworth \& Gilmore, 1979). The present experiments were designed to investigate the effects of such a local application of sympathomimetic drugs on (1) fertility and libido of male rats and (2) sperm numbers in different regions of the genital tract.

\section{Materials and Methods}

Adult Sprague-Dawley rats (males weighing 300-350 g and females weighing 200-250 g) were used. The animals were housed under constant environmental conditions with free access to food (Diet 41B, Millers) and water.

\section{Insertion and removal of collars}

The methods of constructing Silastic (Dow Corning Corp., Michigan, U.S.A.) collars containing drugs and of inserting them round the vas deferens of rats are described by Ratnasooriya et al. (1979). A collar containing $25 \%$ methoxamine hydrochloride (5 rats), $50 \%$ tyramine hydrochloride (6 rats), $75 \%$ tyramine hydrochloride (7 rats), $50 \%$ norephedrine hydrochloride (6 rats) or no drug (5 rats) was placed around each vas deferens. In another group of 3 rats, a collar containing $50 \%$ tyramine was inserted around just one vas deferens.

* Reprint requests to Dr R. M. Wadsworth.

† Present address: Department of Zoology, Colombo Campus, University of Sri Lanka, Colombo 3, Sri Lanka. 
In a different group of animals, two collars containing $50 \%$ norephedrine hydrochloride ( 2 rats), $50 \%$ tyramine hydrochloride (4 rats) or $75 \%$ tyramine hydrochloride ( 1 rat) were placed in the abdominal cavity, near the pelvic viscera, using similar surgical techniques to those described previously. The collars were anchored to the inner surface of the abdominal wall by means of a $2 / 0$ silk suture in 2 of the 5 rats in the $50 \%$ tyramine group.

Collars containing 50\% tyramine hydrochloride ( 7 rats) and 50\% norephedrine (10 rats) were implanted around each vas deferens in the manner previously described. The animals were mated subsequently on Days 3 and 7 after surgery. On Day 10 after surgery, a second operation was performed in which both vasa deferentia were exposed and the connective tissue sheath, which had by then usually grown around the collars, was cut open and the collars were removed. Care was taken not to damage the vas deferens. When there was doubt about damage to one or both ducts by removal of the collars, the animals were deleted from the study. Fertility tests with these animals were again resumed from the 7 th day after the second operation.

\section{Fertility tests}

The day of operation was designated Day 0 and the date of later procedures (e.g. mating) is defined with respect to this.

The libido and fertility of the treated and control males were tested after operation at times ranging from 3 to 125 days. This was done by pairing each male overnight with 1 or 2 prooestrous females having regular 4-day cycles. Mating was confirmed by the presence of spermatozoa in the vaginal smears and/or the presence of a copulatory plug the following morning. In the absence of these criteria, vaginal smears were taken daily to check for pseudopregnancy. The females were killed or laparotomized 10-12 days post coitum.

The animals were not actually tested on days exactly matching those indicated in Tables 1 and 2; usually two matings were undertaken in the first week after the insertion of collars and thereafter at least at 2-weekly intervals. For simplification, therefore, the results have been placed in the column most closely approximating the number of days post-operatively that these matings took place. Sometimes one result has been entered in more than one column, and these numbers have been identified as such. When a male was allowed to mate with 2 females, the larger number of implantations has been entered into the tables.

From these tables, the mean numbers of implantations found at each date were calculated and used to construct the graphs in Text-fig. 1.

\section{Sperm counts in the male tract}

Sperm counts were made 3 days following the insertion of one $25 \%$ methoxamine hydrochloride collar ( 7 rats), or one $50 \%$ tyramine hydrochloride collar (6 rats) round the right vas and a drug-free collar round the left vas deferens. On Day 3 after the operation the animals were anaesthetized with ether. The excurrent duct from each side was removed and cleared of adhering tissue and the animals were then killed. The vas deferens was removed from the cauda epididymidis and the length of the whole epididymis measured. The caput was separated by dividing the epididymis at the proximal boundary of the central narrow region of the epididymis. The remaining part was placed on $2.5 \mathrm{~mm}$ squared graph paper and divided into two equal lengths which were designated corpus and cauda epididymidis. All the segments including the vas deferens were separately weighed before being placed in $3.5 \mathrm{~cm}$ Petri dishes. In an attempt to expose the contents of the vas deferens, a longitudinal cut was made along its length before dividing it into 8 segments of approximately equal size. Each portion of the epididymis was also divided into 8 pieces of approximately equal size. The tissue was transferred to a glass homogenizer and the Petri dishes thoroughly washed with saline $(0 \cdot 9 \%(\mathrm{w} / \mathrm{v}) \mathrm{NaCl}$ solution). 
A concentrated suspension of spermatozoa was prepared from each segment of the epididymis and the entire vas deferens by gently macerating the tissue in approximately $3 \mathrm{ml}$ saline, with 10 strokes of a Griffiths tube ground glass homogenizer (Baird and Tatlock). Following suitable dilutions, the number of spermatozoa in each region of the duct was determined using the improved Neubauer haemocytometer. The counts were made in duplicate and the average of the two determinations was used. The results were expressed as sperm content $\left(\times 10^{6}\right)$.

\section{Sperm counts in the female tract}

The method was a modification of that described by Matthews \& Adler (1977). Four male rats were individually paired overnight with one mature pro-oestrous female rat each. Vaginal smears were taken on the following morning to check for the presence of spermatozoa. Each female was then anaesthetized with ether and the peritoneal cavity opened with a longitudinal incision in the abdomen. Uterine horns were exposed and freed from adhering tissue. Artery forceps were clamped on each oviduct and on the lower end of the vagina. The pubic symphysis was divided and the entire reproductive tract, including vagina, cervix, uterus and ovaries was removed (with the 3 arterial forceps in place), and transferred to a $10 \mathrm{~cm}$ Petri dish containing saline at $37^{\circ} \mathrm{C}$. A drop of the uterine contents was sucked into a syringe with an 18-gauge needle and transferred to a glass slide for assessment of the motility of any spermatozoa present. The artery forceps were removed and the entire tract was cut open longitudinally from the vagina to the oviducts. The mucosa was scraped to remove any spermatozoa embedded in the wall and the tract was then flushed with saline. The flushings were then transferred to a measuring cylinder and, after suitable dilution, used for sperm counts as described above. Counts were made of repeated ejaculations of the same individual male rat, with not less than 3 days rest between consecutive matings. At least two control counts were made for each rat. Further counts were undertaken on Days 3 and 7 after application of one $25 \%$ methoxamine hydrochloride collar to each vas of 1 rat or one $50 \%$ tyramine hydrochloride collar to each vas of 3 rats.

\section{Histology}

The testes, segments of the epididymis and parts of the vas deferens under the collar and between the collar and the cauda epididymidis were removed under anaesthesia from the 4 rats used to estimate sperm counts in the female tract. The tissues were fixed in Bouin's fluid for subsequent histological examination. Sections were cut at $7 \mu \mathrm{m}$ and then stained with haematoxylin and eosin before microscopic examination at $\times 100$ and $\times 400$ magnification.

Spermatozoa from the cauda epididymidis were examined immediately before fixation and their index of motility scored.

\section{Statistics}

The significance of differences between the treated and the control groups was assessed by Mann-Whitney or Wilcoxon rank-sum non-parametric tests (Siegel, 1956), taking $P<0.05$ as significant.

\section{Results}

Fertility tests

These results are shown in Tables 1 and 2.

Control collars ( 1 around each vas). All 5 control rats were fertile as shown by the normal number of implantations in the females with which they were mated. No abnormalities were encountered amongst the litters born from 2 of the mated females.

Methoxamine collars ( 1 around each vas). Of the 15 rats in this group, only 5 survived and all were practically sterile at each of the 7 matings after insertion of the collar $(P<0.01)$. 
Norephedrine collars ( 1 around each vas). All 6 rats in this group were infertile at their first mating after insertion of the collars, but a subsequent partial return of fertility occurred in 3 rats after the 2nd or 3rd week (compared with the control group, Day 3 and Week $1, P<0.01$; Weeks 2 and $3, P<0.05$ ). These 3 rats which spontaneously regained fertility again became sterile 4 weeks after the operation. At autopsy after 16-24 weeks, all the animals in the group had granulomata in both vasa deferentia proximal to the collars.

Tyramine collars ( 1 around each vas). Of the 6 rats studied with 50\% tyramine collars, none was fertile at the first mating but spontaneous recovery of fertility was subsequently observed in 4 rats. The average number of implantations recorded for the group was significantly lower than that of the control group on Day $3(P<0.01)$ and on Weeks 1,2 and $3(P<0.05)$, but at later matings (Weeks 4,6 and 8 ) there was no significant difference.

In 2 rats which recovered fertility, the collars were replaced by new $50 \%$ tyramine collars in Week 9 and both animals subsequently became sterile again. One regained fertility 18 days later but the other remained infertile for the rest of the study (100 days).

Of the 7 animals treated with $75 \%$ tyramine collars, one died as a result of a fight on Day 8 . All but one rat were permanently sterile $(P<0.01$ compared with the control group) and at autopsy were found to have bilateral granulomata.

Table 1. The implantation numbers* in female rats allowed to mate with males at various times after treatment with drug-impregnated collars round the vas deferens

\begin{tabular}{|c|c|c|c|c|c|c|c|c|}
\hline \multirow{2}{*}{$\begin{array}{l}\text { Additive } \\
\text { to } \\
\text { collar }\end{array}$} & \multirow[b]{2}{*}{ Animal } & \multicolumn{7}{|c|}{ Time after operation } \\
\hline & & 3 days & 1 week & 2 weeks & 3 weeks & 4 weeks & 6 weeks & 8 weeks \\
\hline None (control) & $\begin{array}{l}10 \\
11 \\
17 \\
40 \\
41\end{array}$ & $\begin{array}{l}14 \\
13 \\
13 \\
14 \\
11\end{array}$ & $\begin{array}{c}(14) \\
13 \\
13 \\
(14) \\
(11)\end{array}$ & $\begin{array}{c}14 \\
(13) \\
14 \\
12 \\
14\end{array}$ & $\begin{array}{c}14 \\
(13) \\
14 \\
(12) \\
14\end{array}$ & $\begin{array}{c}14 \\
14 \\
(14) \\
7 \\
8\end{array}$ & $\begin{array}{c}(14) \\
12 \\
12 \\
13 \\
(8)\end{array}$ & $\begin{array}{c}14 \\
12 \\
12 \\
(13) \\
8\end{array}$ \\
\hline $\begin{array}{l}\text { Methoxamine } \\
(25 \%)\end{array}$ & $\begin{array}{l}30 \\
46 \\
80 \\
81 \\
82\end{array}$ & $\begin{array}{l}0 \\
0 \\
0 \\
0 \\
0\end{array}$ & $\begin{array}{c}0 \\
0 \\
0 \\
(0) \\
0\end{array}$ & $\begin{array}{c}(0) \\
0 \\
0 \\
0 \\
(0)\end{array}$ & $\begin{array}{c}2 \\
(0) \\
0 \\
0 \\
0\end{array}$ & $\begin{array}{c}(2) \\
0 \\
0 \\
(0) \\
0\end{array}$ & $\begin{array}{c}3 \\
0 \\
(0) \\
0 \\
2\end{array}$ & $\begin{array}{c}0 \\
1 \\
(0) \\
0 \\
2\end{array}$ \\
\hline $\begin{array}{l}\text { Norephedrine } \\
(50 \%)\end{array}$ & $\begin{array}{l}27 \\
28 \\
29 \\
31 \\
32 \\
33\end{array}$ & $\begin{array}{l}0 \\
0 \\
0 \\
0 \\
3 \\
1\end{array}$ & $\begin{array}{c}0 \\
0 \\
0 \\
8 \\
(3) \\
1\end{array}$ & $\begin{array}{c}(0) \\
0 \\
8 \\
0 \\
13 \\
2\end{array}$ & $\begin{array}{c}0 \\
(0) \\
(8) \\
13 \\
(13) \\
(2)\end{array}$ & $\begin{array}{l}2 \\
0 \\
1 \\
0 \\
2 \\
0\end{array}$ & $\begin{array}{c}2 \\
0 \\
1 \\
(0) \\
(2) \\
0\end{array}$ & $\begin{array}{c}0 \\
0 \\
(1) \\
0 \\
0 \\
1\end{array}$ \\
\hline $\begin{array}{l}\text { Tyramine } \\
(50 \%)\end{array}$ & $\begin{array}{l}13 \\
14 \\
21 \\
22 \\
37 \\
38\end{array}$ & $\begin{array}{l}0 \\
0 \\
0 \\
0 \\
0 \\
0\end{array}$ & $\begin{array}{c}13 \\
2 \\
0 \\
0 \\
0 \\
(0)\end{array}$ & $\begin{array}{c}15 \\
1 \\
1 \\
(0) \\
0 \\
2\end{array}$ & $\begin{array}{c}13 \\
1 \\
4 \\
8 \\
(0) \\
(2)\end{array}$ & $\begin{array}{c}13 \\
0 \\
(4) \\
13 \\
0 \\
(2)\end{array}$ & $\begin{array}{r}9 \\
0 \\
14 \\
14 \\
0 \\
6\end{array}$ & $\begin{array}{c}(9) \\
0 \\
(14) \\
(14) \\
0 \\
6\end{array}$ \\
\hline $\begin{array}{l}\text { Tyramine } \\
(75 \%)\end{array}$ & $\begin{array}{l}15 \\
16 \\
20 \\
45 \\
55 \\
34 \\
35\end{array}$ & $\begin{array}{l}0 \\
0 \\
0 \\
0 \\
0 \\
0 \\
0\end{array}$ & $\begin{array}{c}0 \\
0 \\
0 \\
0 \\
0 \\
(0) \\
0\end{array}$ & $\begin{array}{c}- \\
0 \\
0 \\
(0) \\
(0) \\
(0) \\
(0)\end{array}$ & $\begin{array}{c}- \\
0 \\
4 \\
(0) \\
(0) \\
3 \\
0\end{array}$ & $\begin{array}{c}- \\
0 \\
(4) \\
0 \\
0 \\
0 \\
0\end{array}$ & $\begin{array}{l}-0 \\
0 \\
7 \\
0 \\
0 \\
0\end{array}$ & $\begin{array}{c}- \\
0 \\
0 \\
(7) \\
0 \\
0 \\
0\end{array}$ \\
\hline
\end{tabular}

*Each male was tested with 1 or 2 females; when there were 2 females the higher implantation number is given. Parenthetic values are duplicates of tests actually carried out between the times given (see text). 
Table 2. The implantation numbers* in female rats allowed to mate at various times with males after treatment with 2 drug-impregnated collars in the abdomen

\begin{tabular}{lcccccccc}
\hline \multicolumn{1}{c}{$\begin{array}{c}\text { Additive } \\
\text { to } \\
\text { collar }\end{array}$} & Animal & & \multicolumn{7}{c}{ Time after operation } \\
\cline { 5 - 9 } & 3 days & 1 week & 2 weeks & 3 weeks & 4 weeks & 6 weeks & 8 weeks \\
\hline $\begin{array}{l}\text { Tyramine } \\
(75 \%)\end{array}$ & 36 & 12 & 12 & $(12)$ & 12 & 13 & $(13)$ & 11 \\
\hline $\begin{array}{l}\text { Tyramine } \\
(50 \%)\end{array}$ & 39 & 0 & $(0)$ & 2 & 11 & 15 & 15 & 13 \\
& 42 & 11 & 11 & 13 & 12 & $(12)$ & 12 & $(12)$ \\
& 43 & $(17)$ & $(17)$ & 10 & 6 & $(6)$ & 11 & $(11)$ \\
& 44 & $(12)$ & $(12)$ & 8 & 9 & $(9)$ & 9 & 9 \\
\hline $\begin{array}{l}\text { Norephedrine } \\
(50 \%)\end{array}$ & 49 & 8 & 10 & 10 & - & - & - & - \\
\hline
\end{tabular}

* See footnote to Table 1.

Collars in the abdomen (50\%, 75\% tyramine and 50\% norephedrine). No significant reduction in fertility was seen in any of these animals (Table 2) and no gross abnormalities were noticed in the litters resulting from the matings with males which had been given $50 \%$ tyramine collars.

Removal of collars 10 days after insertion (50\% tyramine and 50\% norephedrine). Of the 7 animals with tyramine collars, 2 had to be killed because of the development of an unrelated skin rash. Four of the remainder regained fertility but the other developed granulomata in both vasa deferentia (Text-fig. 1a). In 6 of the 10 rats with norephedrine collars, removal was unsuccessful. Only one of the remaining 4 became fertile. The other 3 developed granulomata in the vasa deferentia (Text-fig. 1a). Norephedrine collars were also removed on Day 21 from 2 animals which had not regained fertility in the main mating study (Table 1). However, no subsequent restoration of fertility was observed.

Tyramine (50\%) collars ( 1 around one vas, contralateral untreated). With the exception of one mating on Day 3 which resulted in only 3 implantations, the numbers of implantations in the 3 animals in the group were not affected by the treatment (Text-fig. Ib), although in Week 7 all had granulomata under the collar on the treated side.

\section{Ability to mate}

There was no apparent reduction in libido because the mating response of the treated males was as vigorous as in control animals, with the usual nudging and sniffing of the females and typical mounting behaviour. Confirmation of mating was obtained in all cases by the presence of spermatozoa in a vaginal smear and/or by consistent dioestrus and the presence of corpora lutea in the ovary at laparotomy.

\section{Sperm counts in the male tract}

Tyramine collars. The most consistent effect seen in the 6 rats of this group, 3 days after surgery, was a significant reduction $(P<0.05)$ in sperm numbers in the corpus epididymidis and the whole epididymis (Table 3 ). In the caput and cauda, the effects were inconsistent, suggesting that the drug did not have the same effect in all the animals.

Methoxamine collars. In the 7 rats investigated 3 days after the operation, there was a significant reduction in sperm numbers in the cauda and in the whole epididymis and a significant increase in the numbers present in the vas deferens of the treated side (Table 3). The effect of the treatment on the sperm content of the corpus and caput epididymidis was more variable and did not reach statistical significance. 


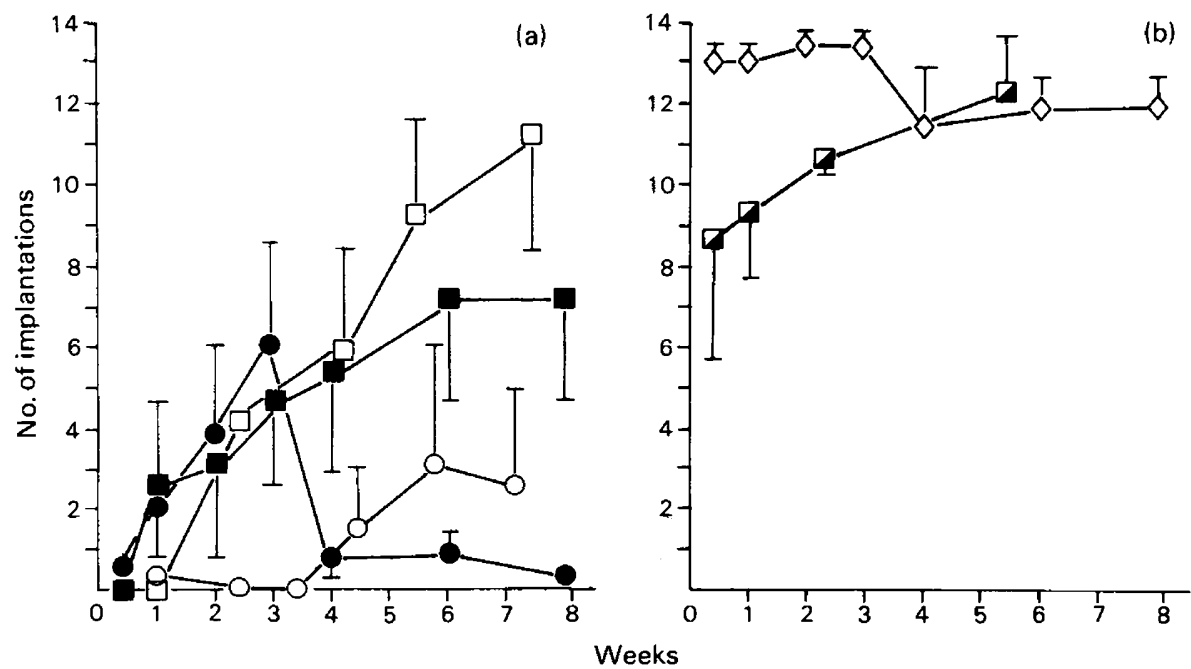

Text-fig. 1. The effect on mean \pm s.e.m. numbers of implantations in females mated, from 3 days after operation, serially with males fitted with Silastic collars round the vas deferens.

(a) Application and removal of collars. One $50 \%$ norephedrine collar inserted round each vas (6 males); $O$, one $50 \%$ norephedrine collar inserted round each vas, and removed at a second operation 10 days later (4-10 males); $\square$ one $50 \%$ tyramine collar inserted round each vas (6 males); $\square$, one $50 \%$ tyramine collar inserted round each vas, and removed at a second operation 10 days later (5-7 males).

(b) Unilateral application of collars. $\square$, One $50 \%$ tyramine collar inserted round one vas, the contralateral side being untreated ( 3 males); $\diamond$, one drug-free (control) collar inserted round each vas ( 5 males). Compare with the values for $50 \%$ tyramine collars $(\square)$ round both vasa deferentia in (a).

\section{Histological observations}

Methoxamine collars. No obvious alteration in spermatogenesis was noticed in the testes of the 3 rats examined 7 days after the insertion of collars. No disorganization of the epithelium of the epididymis was observed. The lumen contained varied numbers of spermatozoa depending on the region observed. The portion of the vas deferens between the collar and the epithelium showed no apparent change with regard to the structure of the epithelium, muscle wall or lumen.

Table 3. Effect of tyramine or methoxamine treatment via a collar placed round the right vas deferens on the sperm distribution in the genital tract of male rats

\begin{tabular}{lccccc}
\hline & \multicolumn{3}{c}{ Total sperm number $\left(\times 10^{6}\right)$} \\
\cline { 2 - 3 } & \multicolumn{2}{c}{$50 \%$ Tyramine } & & $25 \%$ Methoxamine \\
\cline { 2 - 3 } \cline { 5 - 6 } & $\begin{array}{c}\text { Control } \\
\text { (left) }\end{array}$ & $\begin{array}{c}\text { Treated } \\
\text { (right) }\end{array}$ & & $\begin{array}{c}\text { Control } \\
\text { (left) }\end{array}$ & $\begin{array}{c}\text { Treated } \\
\text { (right) }\end{array}$ \\
\hline Caput epididymidis & $123 \pm 16$ & $99 \pm 13$ & & $80 \pm 13$ & $56 \pm 12$ \\
Corpus epididymidis & $33 \pm 6$ & $16 \pm 2^{*}$ & & $3 \pm 0.5$ & $1 \pm 0.6$ \\
Cauda epididymidis & $202 \pm 37$ & $174 \pm 3$ & $89 \pm 22$ & $44 \pm 8^{*}$ \\
Whole epididymis & $358 \pm 49$ & $289 \pm 37^{*}$ & & $172 \pm 41$ & $102 \pm 19^{*}$ \\
Vas deferens & $23 \pm 3$ & $14 \pm 6$ & & $5 \pm 2$ & $18 \pm 6^{*}$ \\
\hline
\end{tabular}

Values are mean \pm s.e.m. for 6 (tyramine) or 7 (methoxamine) rats.

* Significantly different from value on control side (drug-free collar) at $P<0.05$ (Wilcoxon test). 


\section{PLATE 1}
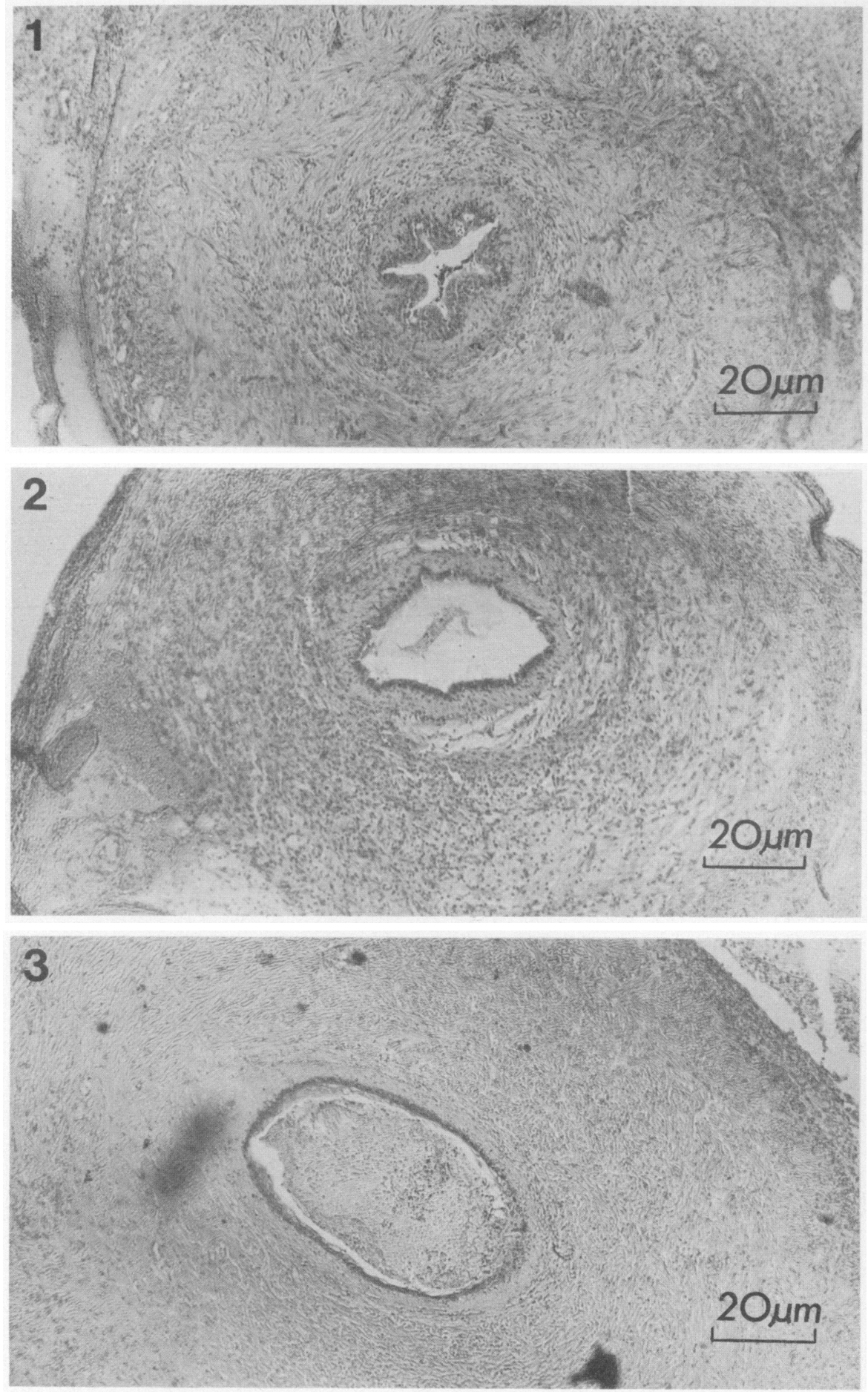

Transverse sections of rat vas deferens stained with haematoxylin and eosin.

Fig. 1. Untreated control.

Fig. 2. After 8 days from insertion of a $50 \%$ tyramine collar, the epithelial lining of the vas immediately under the collar shows only slight damage and a lumen is still present.

Fig. 3. Section of vas under a $25 \%$ methoxamine collar 8 days after insertion. The lumen is occluded completely with fibrous material and the epithelial lining is severely damaged. 
In contrast, the epithelial lining of the vas deferens immediately under the collar showed various degrees of damage, and there was partial to complete blockage of the lumen with fibrous material, but there was no damage to the muscle layers (Plate 1).

Tyramine collars. In 2 rats examined 8 days after insertion of the collars, spermatogenesis appeared to be progressing normally. No damage to the epithelium of the epididymis was observed. In one animal a few spermatids were also found amongst the spermatozoa in the lumen of the epididymis. The appearance of the vas deferens between collar and epididymis was normal. Spermatozoa were present in the lumen. Some damage to the epithelial lining (disintegration and sloughing) under the collar was noticed, but in all cases a lumen was present.

\section{Motility of epididymal spermatozoa}

The spermatozoa from the cauda epididymidis were totally immotile 8 days after insertion of a $50 \%$ tyramine or a $25 \%$ methoxamine collar around each vas deferens.

\section{Sperm counts in the female tract}

For 3 different males rats, the sperm content of the ejaculate was $1.5,15$ and $62 \times 10^{6}$. No spermatozoa were present in the ejaculate at 3 or 7 days after insertion of one $50 \%$ tyramine collar round each vas. A fourth rat, which had an ejaculate content of $98 \times 10^{6}$ spermatozoa, was fitted with a $25 \%$ methoxamine collar round each vas. This animal also had azoospermic ejaculates during the first week after operation.

\section{Discussion}

Application of collars containing $25 \%$ methoxamine, $50 \%$ and $75 \%$ tyramine or $50 \%$ norephedrine to the vasa deferentia of rats caused a loss of fertility which was permanent with methoxamine and with the higher dose of tyramine. On the other hand, norephedrine or the lower dose of tyramine caused only a temporary inhibition of fertility. None of these drugs reduced the ability of the animals to mate. The peak effect on fertility with the lower dose of tyramine was seen up to 1 week following the insertion of collars. There was then a spontaneous restoration of fertility which was probably due to exhaustion of the drug, since the replacement of the collars with new ones caused the animals to become sterile once again. A similar trend was seen with norephedrine treatment, but a second phase of permanent infertility occurred, perhaps due to a mechanical obstruction in the vas deferens.

No impairment of spermatogenesis was observed histologically. In any case this could not explain the antifertility effects because of their rapid onset (3 days) and reversibility (7-10 days) following the application and removal respectively of drug-containing collars.

Since the collars caused a significant reduction in sperm numbers in the cauda epididymidis (methoxamine) or in the whole epididymis (tyramine), it is likely that sperm transport through the ductular system was accelerated. This could have resulted from rhythmic contractions in the vas (Ratnasooriya et al., 1979) and in the epididymis (Hib, 1976, 1977) induced by the drugs released from the collars. In spite of unaltered sperm production and the presence of sufficiently large numbers of spermatozoa in the cauda epididymidis, spermatozoa were not present in the ejaculate. This could result from the sperm outflow being mechanically blocked or by some deficiency in the mechanisms which expel spermatozoa at copulation.

With the methoxamine collars, a mechanical occlusion was produced in the vas beneath the collars by an ingrowth of fibrous material, as revealed by the histological studies. In contrast, such a blockade did not occur following the application of $50 \%$ tyramine collars, suggesting therefore some failure in the ejaculatory process. This failure could have resulted from a 
depletion of endogenous noradrenaline in the adrenergic nerve plexus in the vas deferens (ElBadawi \& Schenk, 1962; Norberg, Risley \& Ungerstedt, 1967) or receptor-specific desensitization (Wadsworth, 1974), either of which would lead to diminished contractions in the vas deferens. An alternative explanation for the lack of spermatozoa in the ejaculate would be a blockage resulting from sustained contraction in the vas created by this method of local administration of the drug.

Vas ligation does not cause a significant rise in sperm numbers in the blocked section of the duct, but it does cause decapitation of spermatozoa (Kuwahara \& Frick, 1975; Ratnasooriya, 1978). Thus the methoxamine-induced rise in sperm numbers in the vas deferens cannot have been due solely to obstruction and may indicate an additional effect, perhaps the expulsion of spermatozoa from the epididymis. Furthermore, methoxamine treatment caused much less decapitation than vas ligation, again indicating that the effects of methoxamine cannot be entirely explained by occlusion of the vas deferens.

When the drugs were administered into the peritoneal cavity or locally to one vas deferens, they failed to reduce fertility. The lack of an effect after abdominal administration shows that the action of the collars is local and cannot be explained by systemic absorption of the drug leading to an effect elsewhere in the animal or influencing its general health. The experiment with a unilateral collar suggests a similar conclusion: that each collar influences the sperm output on its own side of the body. Therefore with only one collar, fertility is maintained by sperm output from the untreated side.

The sympathomimetic drugs tested were administered in the form of Silastic collars in order to obtain a long-lasting effect. However, this method of administration suffers from the disadvantages that the effective dose is not known and there are severe, albeit short-lasting, cardiovascular effects (Ratnasooriya et al., 1979). For methoxamine, these effects were so severe that most treated animals died. However, those which did survive the initial cardiovascular effects were subsequently able to mate, although rendered infertile by the treatment.

We thank Dr Mary Hay, Dr H. Dott and Mr D. W. Richardson for helpful advice and discussion. Financial support was provided by the Scottish Hospitals Endowments Research Trust, and methoxamine was donated by the Wellcome Research Laboratories. W.D.R. was supported by an open scholarship from the Association of Commonwealth Universities.

\section{References}

Anton, P.G. \& McGrath, J.C. (1977) Further evidence for adrenergic transmission in the human vas deferens. J. Physiol., Lond. 273, 45-55.

El-Badawi, A. \& Schenk, E.A. (1962) The distribution of cholinergic and adrenergic nerves in the mammalian epididymis. A comparative histochemical study. $\mathrm{Am}$. J. Anat. 121, 1-14.

Hepperlen, T.W., Dalske, H.F. \& Lacy, S.S. (1976) Effects of prostaglandins, nitrofurantoin and Escherichia coli on response of human vas deferens to norepinephrine. Fert. Steril. 27, 275-281.

Hib, J. (1976) Effects of autonomic drugs on epididymal contractions. Fert. Steril. 27, 951-956.

Hib, J. (1977) The 'in vivo' effects of oxytocin and vasopressin on spontaneous contractility of the rat epididymis. Int. J. Fert. 22, 63-64.

Kuwahara, M. \& Frick, J. (1975) The ligation of the male reproductive organs and the role of the spermatic cyst. Andrologia 1, 1-14.

Martins, T., Valle, J.R. \& Porto, A. (1940) Phar- macology in vitro of the human vas deferens and epididymis; the question of the endocrine control of the motility of the male accessory genitals. J. Urol. 44, 682-698.

Matthews, M. \& Adler, N.T. (1977) Facilitative and inhibitory influences of reproductive behaviour on sperm transport in rats. J. comp. Physiol. Psychol. 91, 727-741.

McLeod, D.G., Reynolds, D.G. \& Demaree, G.E. (1973) Some pharmacological characteristics of the human vas deferens. Invest. Urol. 10, 338-341.

Norberg, K.A., Risley, P.L. \& Ungerstedt, U. (1967) Adrenergic innervation of the male reproductive ducts in some mammals. II. Effects of vasectomy and castration. Experientia 23, 392-394.

Ratnasooriya, W.D. (1978) Effects of sympathomimetic drugs on the contractility of the vas deferens and on fertility in the male rat and rabbit. Ph.D. thesis, University of Strathclyde.

Ratnasooriya, W.D., Wadsworth, R.M. \& Gilmore, D.P. 
(1979) The effect of sympathomimetic drugs on contractility of the vas deferens in vitro and in vivo. J. Reprod. Fert. 56, 633-641.

Siegel, S. (1956) Non-parametric Statistics for the Behavioral Sciences. McGraw-Hill, New York.

Ventura, W.P., Freund, M. Davis, J. \& Pannati, C.
(1973) Influence of norepinephrine on the motility of the human vas deferens; a new hypothesis of sperm transport by the vas deferens. Fert. Steril. 24, 68-77.

Wadsworth, R.M. (1974) Excitatory and inhibitory effects of noradrenaline on the isolated guinea-pig vas deferens. Clin. exp. Pharmac. Physiol. 1, 135-145.

Received 11 December 1978 